\title{
Observations of bedforms on a dissipative macrotidal beach
}

\author{
Jon Miles • Antony Thorpe • Paul Russell • \\ Gerd Masselink
}

Received: 25 September 2013 / Accepted: 2 December 2013 /Published online: 11 January 2014

(C) Springer-Verlag Berlin Heidelberg 2014

\begin{abstract}
Field measurements of wave ripples and megaripples were made with a Sand Ripple Profiler in the surf and shoaling zones of a sandy macrotidal dissipative beach at Perranporth, UK in depths $1-6 \mathrm{~m}$ and significant wave heights up to $2.2 \mathrm{~m}$. A frequency domain partitioning approach allowed quantification of height $(\eta)$, length $(\lambda)$ and migration rate of ripples and megaripples. Wave ripples with heights up to $2 \mathrm{~cm}$ and wavelengths $\sim 20 \mathrm{~cm}$ developed in low orbital velocity conditions $\left(u_{\mathrm{m}}<0.65 \mathrm{~m} / \mathrm{s}\right)$ with mobility number $\psi<25$. Wave ripple heights decreased with increasing orbital velocity and were flattened when mean currents were $>0.1 \mathrm{~m} / \mathrm{s}$. Wave ripples were superimposed on top of megaripples $(\eta=10 \mathrm{~cm}$, $\lambda=1 \mathrm{~m}$ ) and contributed up to $35 \%$ of the total bed roughness. Large megaripples with heights up to $30 \mathrm{~cm}$ and lengths $1-$ $1.8 \mathrm{~m}$ developed when the orbital velocity was $0.5-0.8 \mathrm{~m} / \mathrm{s}$, corresponding to mobility numbers $25-50$. Megaripple heights and wavelengths increased with orbital velocity but reduced when mean current strengths were $>0.15 \mathrm{~m} / \mathrm{s}$. Wave ripple and megaripple migrations were generally onshore directed in the shoaling and surf zones. Onshore ripple migration rates increased with onshore-directed $(+v e)$ incident wave skewness. The onshore migration rate reduced as offshore-directed mean flows (undertow) increased in strength and reached zero when the offshore-directed mean flow was $>0.15 \mathrm{~m} / \mathrm{s}$. The migration pattern was therefore linked to cross-shore position relative to the surf zone, controlled by competition between onshoredirected velocity skewness and offshore-directed mean flow.
\end{abstract}

Responsible Editor: Bruno Castelle

This article is part of the Topical Collection on the 7th International Conference on Coastal Dynamics in Arcachon, France 24-28 June 2013

J. Miles $(\bowtie) \cdot$ A. Thorpe $\cdot$ P. Russell $\cdot$ G. Masselink

School of Marine Science and Engineering, Plymouth University,

Devon PL4 8AA, UK

e-mail: jrmiles@plymouth.ac.uk
Keywords Surf zone $\cdot$ ripples $\cdot$ megaripples $\cdot$ ripple migration · Sand Ripple Profiler · dissipative beach

\section{Introduction}

In sandy marine environments, ripples on the seabed develop in a variety of conditions and make an important contribution to bottom boundary layer hydrodynamics and sediment transport (Dyer 1986). However, the conditions for their development and migration on macrotidal dissipative beaches are not well understood.

In wave-dominated conditions, ripples may develop with a typical wavelengths $\lambda$ of $\sim 0.05-0.5 \mathrm{~m}$ and heights $\eta$ of $\sim 0.01-0.1 \mathrm{~m}$ (e.g. Nielsen 1992; Gallagher et al. 2005). They are typically symmetrical in shape (Masselink and Hughes 2003), and their steepness indicates their classification as either post-vortex ripples with $\eta / \lambda<0.15$ or vortex ripples with $\eta / \lambda=0.15$ (Bagnold 1963). In unidirectional currents, bedforms evolve as shear stress increases, through a sequence of low stage flat bed ripples, current dunes, upper stage plane bed and finally antidunes (Dyer 1986; Nielsen 1992). Ripples in unidirectional flows scale with typical lengths of 0.1 to $0.2 \mathrm{~m}$ and heights up to $0.06 \mathrm{~m}$ (Allen 1968). Yalin (1964) parameterized ripple length from the grain size $(\lambda=1,000 \mathrm{D})$ and ripple height as $\eta=\lambda / 7$. Current dunes have typical wavelengths of 0.6 to $30 \mathrm{~m}$ and heights of 0.06 to $1.5 \mathrm{~m}$. Dune length is governed by water depth $\mathrm{h}$, as $\lambda=2 \pi \mathrm{h}$, and dune height scales to maximum of $\mathrm{h} / 6$ (Yalin 1964). In high flows and shallow depths, under supercritical flow conditions, bedforms may migrate against the flow direction, in which case they are known as antidunes (Dyer 1986).

Approaching the surf zone from offshore, wave ripples that typically form in deeper water give way to megaripple features in the surf zone, which have larger wavelengths and heights (Clifton et al. 1971). Typical heights of the megaripples are 0.1 
to $1 \mathrm{~m}$, and lengths are 0.5 to $5 \mathrm{~m}$ (Gallagher et al. 1998; Gallagher 2003). In megaripple-dominated surf zones, field measurements show that the bed roughness (i.e. bedform height) is largest at moderate mobility numbers (Gallagher et al. 2003). Wave orbital velocity is a key parameter in determining bedform type. Hay and Mudge (2005) identified that megaripples existed when root mean square (RMS) wave orbital velocities were approximately $>0.28 \mathrm{~m} / \mathrm{s}$, while linear transition ripples existed when RMS orbital velocities were in an approximate range 0.19 to $0.31 \mathrm{~m} / \mathrm{s}$. Bedform type was independent of wave velocity skewness, velocity asymmetry and longshore current strength (Hay and Mudge 2005). Megaripples are reported as three-dimensional, and although they may take on a regular alongshore structure, they may develop as lunate features (Hay and Mudge 2005) or as hummocks and holes in a less regular distribution (Gallagher 2003).

Field measurements indicate that megaripple wavelengths do not conform well to the predictive capability of conventional models (Gallagher et al. 2003). Self-organization theory suggests that nearshore bedforms including cusps, ripples and megaripples either grow or remain stable in size, depending on the forcing conditions (Clarke and Werner 2004; Gallagher 2011). Where hydrodynamic conditions do result in bedform modification, the timeframe for change may be long (Soulsby 1997), leading to the potential for the hydrodynamic conditions to be out of equilibrium with the seabed. This may also result in different sorts of bedforms existing at the same time. Dyer (1986) and Blondeaux et al. (2000) identified that in conditions with both waves and currents, the bed may display features of both wave and current ripples. Thornton et al. (1998) observed bedforms in an alongshore trough/rip channel from a large range of conditions at the Duck94 field experiment and found that mild waves and weak currents led to wave ripples, but storm waves and strong longshore currents led to megaripples. Thornton et al. (1998) also identified that newly formed wave ripples co-existed with residual bedforms, to create complex patterns of topography.

The migration rate of ripples has been suggested to depend on mobility number (Vincent and Osborne 1993; Traykovski et al. 1999). The direction of transport and the migration rate has also been shown to follow the wave skewness (Gallagher et al. 1998; Crawford and Hay 2001). Doucette (2002) made visual observations of ripple migration rates on a coarse sandy beach $\left(D_{50}=0.7 \mathrm{~mm}\right)$. The beach was sea breeze dominated, and ripples with heights of $0.05-0.15 \mathrm{~m}$ and lengths of $0.3-1.2 \mathrm{~m}$ were found to migrate onshore at rates of up to $0.2 \mathrm{~cm} / \mathrm{min}$. Masselink et al. (2007) investigated variations in ripple migration rates across the surf zone on a coarse grained sand beach (also $D_{50}=0.7 \mathrm{~mm}$ ) at Sennen, UK and found that migration rate depended on cross-shore location. Ripple heights of $0.05 \mathrm{~m}$ and lengths of $0.35 \mathrm{~m}$ were recorded. Migration rates varied from $0.1 \mathrm{~cm} / \mathrm{min}$ onshore in the shoaling zone to $2 \mathrm{~cm} / \mathrm{min}$ and onshore in the outer surf and no transport in the inner surf. In strong currents, such as feeder currents and rip currents, Sherman et al. (1993) found that lunate megaripples migrated in the same direction as the mean current. In a flow of 0.4 to $0.6 \mathrm{~m} / \mathrm{s}$, depth $0.71 \mathrm{~m}$, wave height $0.65 \mathrm{~m}$, wave period $10.6 \mathrm{~s}$ and $D_{50}=0.33 \mathrm{~mm}$, ripples of length $1.6 \mathrm{~m}$ and height $0.16 \mathrm{~m}$ migrated at $1.65 \mathrm{~cm} / \mathrm{min}$. Ngasuru and Hay (2004) identified that at Duck94, megaripples migrated shoreward under incident wave conditions with orbital velocities in the range 0.5 to $0.8 \mathrm{~m} / \mathrm{s}$ and with low velocity mean currents but stalled and may have migrated offshore when mean offshore flow exceeded $0.2 \mathrm{~m} / \mathrm{s}$.

Field measurements of ripples and megaripples have been made on beaches with different morphological and tidal regimes, including the microtidal beaches at Duck (Gallagher et al. 2003, 2005; Thornton et al. 1998; Ngasuru and Hay 2004), Queensland, Novia Scotia (Crawford and Hay 2001, 2003) and at Scripps (Clarke and Werner 2004), on a mesotidal bar-trough beach at Truc Vert, France (Austin et al. 2007), on coarser sediment macrotidal intermediate beaches, such as Sennen Cove (UK) (Masselink et al. 2007), and in deeper water, such as measurements made on sand ridges in $11 \mathrm{~m}$ water depth by Traykovski et al. (1999). In this paper, detailed new field measurements of bedform sizes and migration rates are presented from a macrotidal, sandy, fine grained and dissipative beach. The dataset offers unique new insight into ripple and megaripple dynamics from relatively deep water $(\sim 6 \mathrm{~m})$ through shoaling wave conditions with skewed waves and into the surf zone where incident waves and offshore-directed undertow combine.

\section{Field measurements}

Field measurements were made at a high energy, macrotidal dissipative sandy beach at Perranporth (North Cornwall, UK) (Fig. 1). Perranporth has a mean tidal range of $6.1 \mathrm{~m}$ and a mean offshore wave height of $1.6 \mathrm{~m}$ (Davidson et al. 1997).

The beach profile was reasonably linear, with an average slope of 0.0125 (Fig. 2). Sediments at the site are medium sand $\left(D_{50}=0.28 \mathrm{~mm}\right)$. Two separate field deployments were carried out in May 2011 and October 2011, each for six separate high tides. The tides described in this paper are identified as tides 11-16 and 21-26, representing the May and October deployments, respectively. Measurements were made by deploying an instrumented rig near the low water mark, roughly between the spring and neap low tide level. By carrying the rig into the water, it was possible to place the instruments just seaward of the spring low water mark in the second deployment. The instruments logged data as the tide flooded and ebbed over the rig, and this allowed measurements to be made in a variety of water depths from 1 to $6 \mathrm{~m}$ and in a variety of wave/current conditions in the surf and shoaling zones. 
On the rig, a Sand Ripple Profiler (SRP) measured a line scan of seafloor elevation (Fig. 3). The SRP was positioned $90 \mathrm{~cm}$ above the bed, and measured a 2-m on-offshore line once per minute. Data was post-processed to give regular horizontal (on-offshore) spacing between points of $\sim 1 \mathrm{~cm}$ over the $2-\mathrm{m}$ footprint of the scanner. Flow velocities were measured using an Acoustic Doppler Velocity meter (ADV), with a sensing volume $25 \mathrm{~cm}$ above the bed. Mean water depths and wave heights were measured using a Pressure Transducer (PT), deployed at bed level. Hydrodynamic data were recorded at $16 \mathrm{~Hz}$ for tides 11-16 and $8 \mathrm{~Hz}$ for tides 21-26. Sediment concentrations were measured with two Optical Backscatter Sensors (OBSs). OBSs were calibrated with sand from the deployment site, using the glycerol based technique of Butt et al. (2002). For the first six tides, OBSs were deployed at 5 and $15 \mathrm{~cm}$; for the second six tides, they were deployed at 25 and $40 \mathrm{~cm}$ above the bed. Data from the ADV, PT and OBSs were divided into 10min runs for processing. Hydrodynamic data were only considered for runs when bedform data from the SRP were available. This limited the data set to water depths greater than $1 \mathrm{~m}$, because only then was the SRP covered by water sufficiently to yield continuous information on the seabed topography.

\subsection{Overview of experiment conditions}

Hydrodynamic conditions for each of the tides recorded at the rig are shown in Fig. 4. Each 'run' represents a 10-min section of data. The run numbers start when data collection started on the first tide. The instruments were dry at low water and between experiments, and these time periods with no data have been removed. There are no time gaps between runs when the instruments were submerged. Wave heights $(H)$ were calculated using a standard $H_{1 / 3}$ zero up-crossing method, having first corrected for depth attenuation. $H$ was in the range 0.48 to $2.19 \mathrm{~m}$. Wave period $(T)$ was calculated as $T_{1 / 3}$. The site experienced mostly swell waves for the measured tides, with $T=10$ to $11 \mathrm{~s}$, although data were also collected for $T=7$ to $8 \mathrm{~s}$ (tides 25 and 26). Values of $H / h$ are minimum in deep water and increase shoreward in shallower water.

Mean cross-shore flows were calculated as 10-min time averages at the ADV (Fig. 5). Values were either close to zero at high tide or offshore directed in shallower water (in the surf zone) at either side of high tide. Mean crossshore flows reached a maximum strength of $-0.34 \mathrm{~m} / \mathrm{s}$. Mean longshore current strengths were up to $0.2 \mathrm{~m} / \mathrm{s}$ and directed to the North on the flood and to the South on the ebb tide.

Oscillatory components of the flow were routinely separated into incident wave (gravity band) and infragravity band oscillations, by applying a frequency domain high/low-pass filter with a cut-off at $0.05 \mathrm{~Hz}$. Orbital velocity was calculated as $u_{\mathrm{m}}=2 \sqrt{ } \sigma^{2}{ }_{\mathrm{u}}$ (where $\sigma_{\mathrm{u}}^{2}$ is the total cross-shore velocity variance) following Masselink et al. (2007). Both the incident wave crossshore velocity variance (not shown) and the orbital velocities (shown) peaked in the shallow water at the start and end of the tide but were modulated by the offshore wave height. Incident wave velocity variance and orbital velocity increased on days when the wave heights were larger and also increased when the water depth over the rig was shallower. A similar pattern was followed by the orbital excursion. Infragravity variance in the cross-shore velocity was generally small at high tide ( $2 \%$ of the total cross-shore velocity variance) but increased in the shallower water in the surf zone (not shown). The maximum infragravity contribution was $17.6 \%$ of the total cross-shore velocity variance (tide 22 , run 224). On other tides, the typical maximum infragravity contribution was $12 \%$.

Unnormalised velocity skewness $\left\langle u^{\prime 3}\right\rangle$ is calculated from the oscillatory component of the cross-shore velocity $\left(u^{\prime}\right)$ and is often used as an indicator of bedload transport in sediment transport models (e.g. Bailard 1981). It contains information on both velocity variance and on wave shape. Skewed waves typically have a shorter duration shoreward stroke than the seaward stroke, but the shoreward component is of greater magnitude, and this can give rise to a net sediment transport. Elgar et al. (1998) identified the normalized skewness component as an indicator of the wave shape that is independent of the velocity variance:

$S_{u}=\frac{\left\langle u^{\prime 3}\right\rangle}{\left\langle u^{\prime 3}\right\rangle^{3 / 2}}$

Crawford and Hay (2001) found only a small difference in the ability of $S_{u}$ and $<u^{\prime 3}>$ to predict ripple migration rate, but in their data, $S_{u}$ was marginally more skillful. In these data, wave skewness $\left(S_{u}\right)$ increased in a more pronounced manner than the orbital velocity in shallow water and reached a maximum of 1.6 in run 272. The unnormalised skewness parameter $<u^{\prime 3}>$ showed a similar trend to $S_{u}$.

Wave asymmetry is defined as the time-averaged skewness of the acceleration time series for the incident wave band (Elgar et al. 1998). This parameter quantifies the sawtooth shape of the velocity associated with the wave and is large if there are large accelerations co-incidental with the leading edge of the wave. No clear pattern was evident in asymmetry in these data, and this may have been because the water was not sufficiently shallow for asymmetric bores typical of the inner surf and swash zone to impact on the velocity signal.

The form of mobility number was chosen such that the influence of both mean and oscillatory components of flow 
Fig. 1 The deployment location (circled) at Perranporth, UK (adapted from Austin et al. (2010))

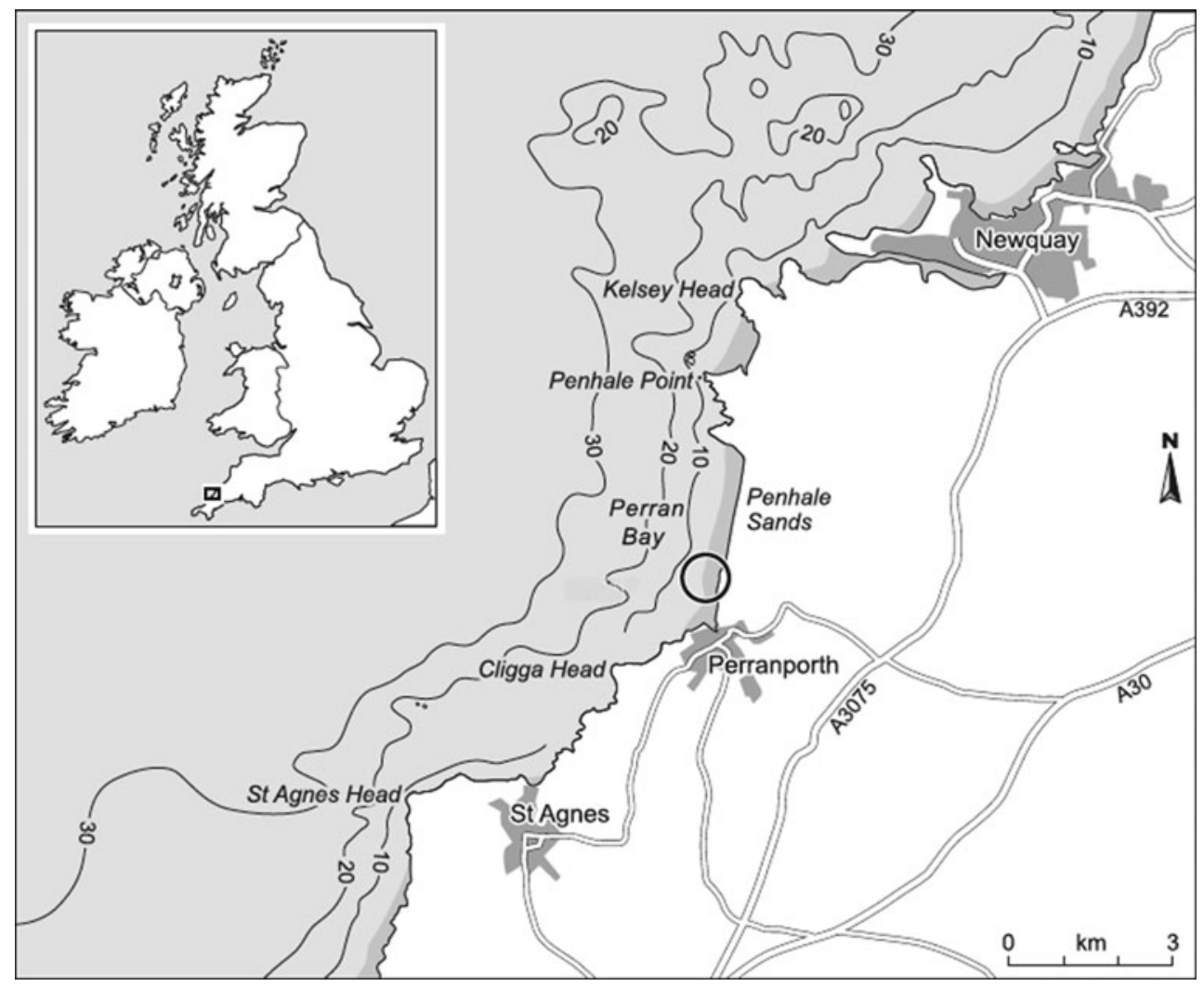

was considered and follows the approach of Gallagher et al. (2003), in which

$\Psi=\frac{\left\langle u^{2}+v^{2}\right\rangle}{(s-1) g D}$

where $u$ and $v$ are the total cross and longshore velocity times series that are temporally averaged $(<>), s$ is the specific gravity of the sediment ( $s=2.65$ for quartz sand), $g$ is the gravitational acceleration and $D$ is the grain diameter. Generally in this experiment, $\psi$ was in the range 0 to 100 . Mobility numbers were lowest when wave heights were small and when the instruments were in deeper water, because both mean and oscillatory flows were small in deeper water.

Sediment concentrations and transport rates are presented here from one height above the bed, to indicate the net transport direction in the mean and oscillatory constituents above the ripple field. In tides 11-16, suspended sediment concentrations were measured at the OBS heights of $z_{1}=5 \mathrm{~cm}$ and $z_{2}=15 \mathrm{~cm}$ above the bed. In tides 21-26, OBSs were set at 25 and $40 \mathrm{~cm}$. In order to standardize the dataset as far as possible, concentration values for tides $11-16$ were predicted at $z_{3}=25 \mathrm{~cm}$ from the OBS data at $z_{1}=5$ and $z_{2}=15 \mathrm{~cm}$ using the Nielsen (1992) exponential concentration curve. For rippled beds, Nielsen (1992) gives the variation concentration with distance from the bed $(\mathrm{z})$ as:

$c_{z}=c_{0} e^{-z / L_{s}}$

where $c_{0}$ is a reference concentration at the bed and $L_{\mathrm{s}}$ is a length-scale representing the vertical diffusivity of the sediment. Run-averaged values of concentration at the two heights measured were used to calculate runaveraged values of $L_{s}$ :
Fig. 2 Beach profiles for the experiment period, showing the rig positions. The position of Mean High Water and Mean Low Water on Spring and Neap tides, respectively, are indicated. ODN refers to Ordnance Datum Newlyn (approximate UK mean sea level datum). Instrument rig locations are identified for the different tides

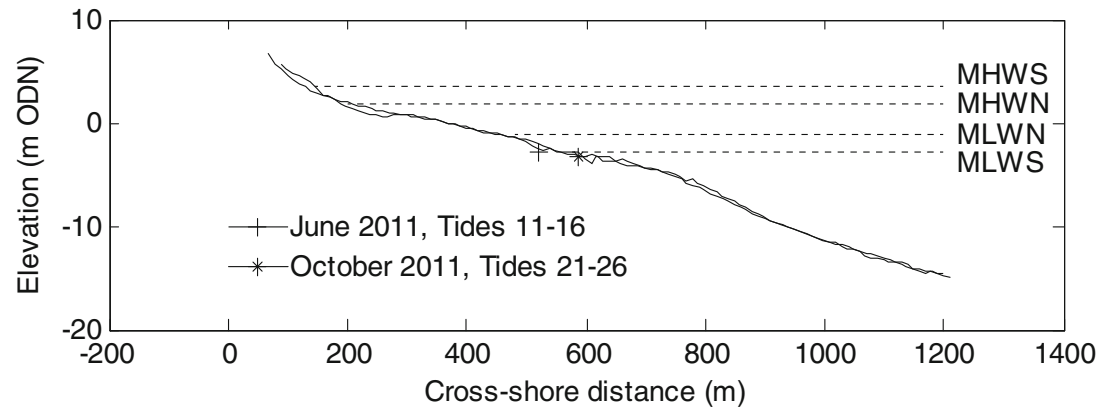




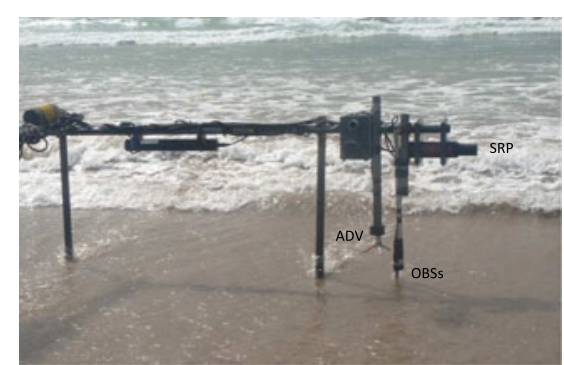

Fig. 3 Photo of instruments deployed showing the position of the Sand Ripple Profiler (SRP), Acoustic Doppler Velocity meter (ADV) and the Optical Backscatter Sensors (OBS). A Pressure Transducer was also mounted on the vertical pole with the OBSs

$L_{s}=\frac{z_{2}-z_{1}}{\log \left\langle c_{1}\right\rangle-\log \left\langle c_{2}\right\rangle}$

From this, the concentration time series at $z_{3}=25 \mathrm{~cm}$ could be calculated directly from the time series of concentration at $z_{1}=5 \mathrm{~cm}$ using

$c_{3}=c_{1} \frac{e^{-z_{3} / L_{s}}}{e^{-z_{1} / L_{s}}}$

Using this approach, the magnitude of the concentration time series is modified, but information relating to the phase of suspension is maintained as far as possible. Time-averaged sediment concentrations indicated that the largest concentrations occurred in the shallow water at the start and end of each tide (Fig. 6).
The time-averaged 'total' sediment transport $(\langle u c\rangle)$ was separated into mean $(\langle u\rangle\langle\mathcal{c}\rangle)$ and oscillatory components (Jaffe et al. 1984). The oscillatory (flux coupling) component $\left.\left(<u^{\prime} c^{\prime}\right\rangle\right)$ was further decomposed into incident wave and infragravity components. Velocity and concentration data were filtered at $0.05 \mathrm{~Hz}$, and gravity $\left\langle u_{g}{ }^{\prime} c_{g}{ }^{\prime}>\right.$ and infragravity $\left.<u_{i g}{ }^{\prime} c_{i g}{ }^{\prime}\right\rangle$ components were calculated from the reconstructed filtered time series (e.g. following Wright et al. 1991). The total transport was considered as

$\langle u c\rangle=\langle u\rangle\langle c\rangle+\left\langle u_{g}^{\prime} c_{g}^{\prime}\right\rangle+\left\langle u_{i g}^{\prime} c_{i g}^{\prime}\right\rangle$

Sediment transport by the mean flow $\langle u\rangle\langle c\rangle$ was generally directed offshore, following the direction of the mean flow $\langle u\rangle$. The infragravity component was also directed offshore for the majority of runs. The gravity wave component was variable in direction and was small in magnitude when compared to the combination of mean plus infragravity components. As a result of the combination of these processes, the total suspended sediment transport was: largest in shallow water at the start and/or the end of the tide; was controlled fundamentally by the mean component; and offshore-directed.

\section{Bedforms}

Sequential profiles from the SRP were time stacked and are displayed as an image plot to illustrate different features of
Fig. 4 Hydrodynamic data, showing water depth $h$, wave height $H$, wave period $T$ and wave height over water depth. Each 'Run' represents a 10-min section of data. Vertical lines indicate when instruments were dry at low tide or between deployments
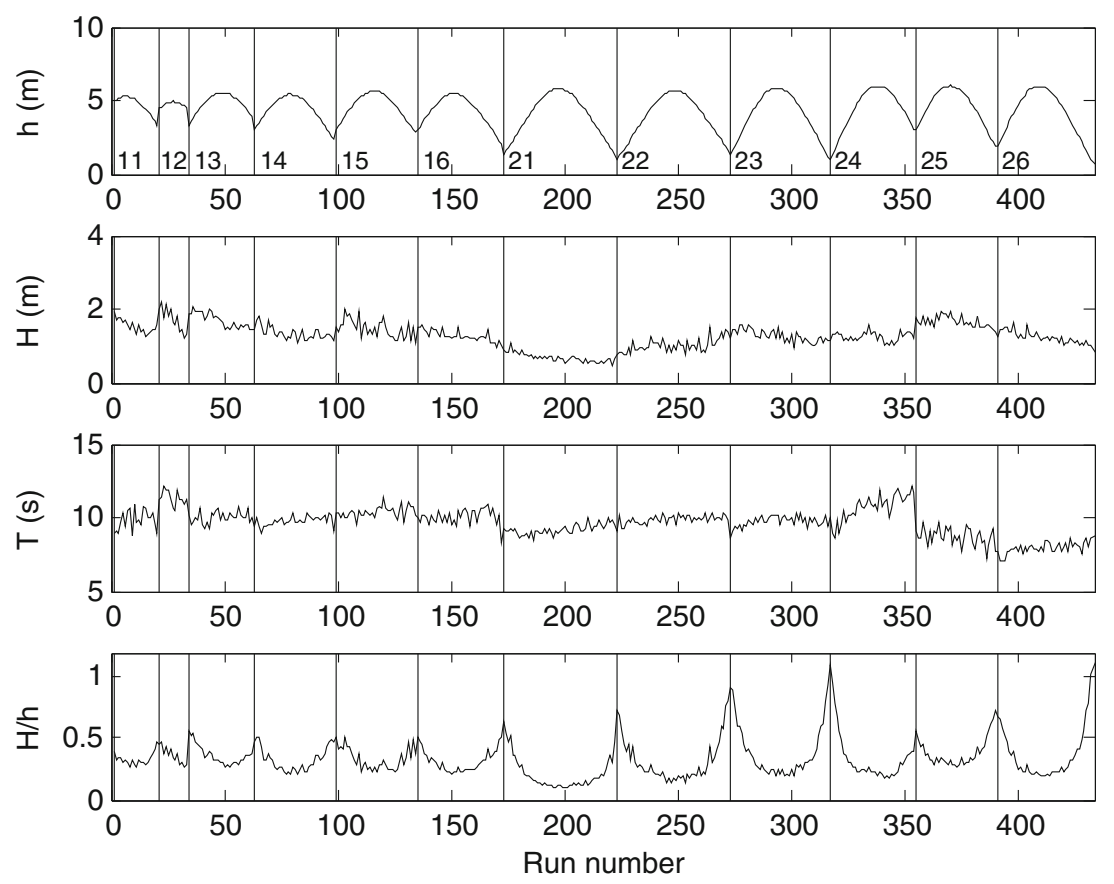
Fig. 5 Velocity parameters: mean (time-averaged) cross-shore velocity $\langle u>(+$ ve onshore), mean longshore velocity $\langle v>$ (+ve to North), orbital velocity $u_{\mathrm{m}}$, normalized short wave velocity skewness $S_{u}$ and mobility number $\psi$
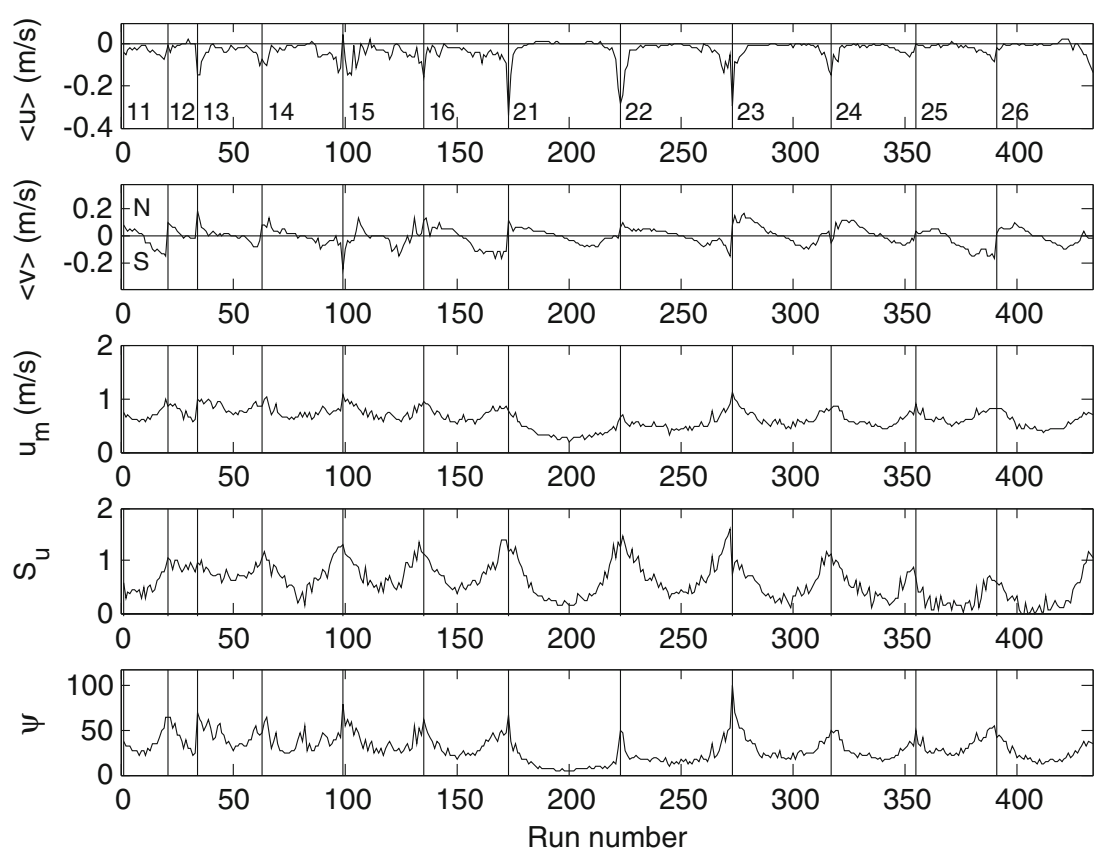

interest (Fig. 7). Megaripples migrated shoreward for the majority of the time (i.e. crests moving down the image as time passes). There are instances where (a) there were mixed wavelengths of ripples present (e.g. tide 21, run 200), (b) where the shoreward migration signal was strong (e.g. tide 22 , run 250) and (c) where minimal movement over high tide was followed by megaripple shoreward migration as the tide ebbs and the water was shallower (e.g. tide 23, run 300 onwards).

Tide 21 gives an example of where wave ripples and megaripples combine in the profile. The bed elevation trace from one cross-shore scan (run 200) is shown in Fig. 8 (top). Wave ripples with wavelength $\sim 20 \mathrm{~cm}$ and a megaripple feature of length $\sim 1 \mathrm{~m}$ are evident. Spectral analysis of the bed elevation indicated two distinct populations of bed features, with ripples of wavelength $\sim 20 \mathrm{~cm}$ and megaripples with wavelengths $>\sim 35 \mathrm{~cm}$. To separate out and quantify the wave ripple component, each bedform scan was high-pass and low-pass filtered using a frequency domain filter, applied with a cut-off wavelength of $35 \mathrm{~cm}$. The output from this filtering approach is shown in Fig. 8 (bottom), illustrating the separation of wave ripple and megaripple components.

In order to parameterise bed roughness, Gallagher et al. (2003) used the RMS bedform roughness, calculated as the square root of the integrated bed level spectrum. Crawford and Hay (2001) identified that the heights of wave ripples and megaripples could be determined directly from the variance of the bed level trace $\left(\sigma^{2}(z)\right)$. The Crawford and Hay (2001) calculation was carried out on the filtered wave ripple and megaripple elevation data here, to give wave ripple, megaripple and total (i.e. unfiltered) bedform height values:

$\eta_{\text {bedform }}=\sqrt{8 \sigma^{2}\left(z_{\text {bedform }}\right)}$

The relative contribution of wave ripples to the total (unfiltered) bed roughness is given by

$F_{\mathrm{wr}}=\sqrt{\frac{\sigma^{2}\left(z_{\mathrm{wave}} \text { ripple }\right)}{\sigma^{2}\left(z_{\mathrm{total}}\right)}}$

Wave ripple contributions were generally small in all but two cases (Fig. 9). In tide 21, the wave ripples are clear in the bedform images and had heights of $\sim 2 \mathrm{~cm}$ with maximum heights at around mid-tide. Wave ripples in the experiment had heights $>1 \mathrm{~cm}$ for $12.9 \%$ of the time. Ripples were $>0.52 \mathrm{~cm}$ for $50 \%$ of the time. The time when the wave ripples were largest co-incided with the lowest wave energy conditions in the experiment. By comparison, megaripples ranged in height from flat bed to $30 \mathrm{~cm}$. They were $>10 \mathrm{~cm}$ for $13.4 \%$ of the time and were greater than $6.58 \mathrm{~cm}$ high for $50 \%$ of the time. The fractional contribution of wave ripples to the overall bed roughness $\left(F_{\text {wr }}\right)$ was largest in tide 21 when wave heights were smallest and reached $35 \%$ when the underlying megaripple was reducing in height as the water reduced in depth. There was also a peak in $F_{\mathrm{wr}}$ in tide 12. The wave ripple contribution appears large in the overall balance at this time, even though the wave ripples were small, because any megaripple scale features were also small.

Ripple wavelengths were calculated as twice the spatial lag corresponding to the strongest negative autocorrelation peak. This was carried out separately for the high and low-pass 
filtered bed data, to give wave ripple and megaripple lengths, respectively (Fig. 10). For the wave ripples, the routine returned a wavelength of $35 \mathrm{~cm}$ (i.e. the edge of the filter) when the bed was flat. For the megaripples, the maximum value was limited by the requirement for at least half a wavelength to be visible within the scan. Wave ripple wavelengths varied from $\sim 10 \mathrm{~cm}$ to the edge of the filter band $(35 \mathrm{~cm})$. The average wavelength of wave ripples $>0.52 \mathrm{~cm}$ high (i.e. the wavelength of highest $50 \%$ of ripples) was $22.9 \mathrm{~cm}$. Megaripple wavelengths were typically in the range 1 to $2 \mathrm{~m}$. When megaripple heights were $>6.58 \mathrm{~cm}$ (i.e. the highest $50 \%$ of megaripples), the average megaripple wavelength was $1.25 \mathrm{~m}$.

The maximum wave ripple steepness was 0.1 . For $\eta_{\mathrm{wr}}>0.52 \mathrm{~cm}$, the average steepness was 0.03 , and for $\eta_{\mathrm{wr}}>$ $1 \mathrm{~cm}$, the average steepness was $\sim 0.066$. The maximum megaripple steepness was 0.18 . For $\eta_{\mathrm{mr}}>10 \mathrm{~cm}$, the average steepness was 0.11 , and for $\eta_{\mathrm{mr}}>6.58 \mathrm{~cm}$, the average steepness was 0.08 .

The hydrodynamic conditions for the existence of megaripples and wave ripples were identified using ripple height data in different mean flows, orbital velocities and for different mobility numbers (Fig. 11). Wave ripple heights were maximum when mean currents were zero. Wave ripples increased in height with reduced incident wave orbital velocity. They were $>1 \mathrm{~cm}$ elevation when the mean flow speed was $<0.1 \mathrm{~m} / \mathrm{s}$ and the orbital velocity was $<0.65 \mathrm{~m} / \mathrm{s}$, corresponding to mobility numbers 26 . There was some evidence that the ripple height increased with water depth; however, this was complicated by the variation in orbital velocities due to vary- ing incident wave conditions (e.g. shoaling and surf zone dissipation) and was not particularly clear. Megaripples were at their maximum height when mean velocities were weak and directed offshore $(\sim 0.05 \mathrm{~m} / \mathrm{s})$. Megaripple heights reduced below $10 \mathrm{~cm}$ when currents exceeded $0.15 \mathrm{~m} / \mathrm{s}$ in strength. The largest megaripples developed when the orbital velocity was in the range 0.55 to $0.8 \mathrm{~m} / \mathrm{s}$, corresponding to a mobility number range of 20 to 50 .

Like the data presented by Hay and Mudge (2005), the wave ripples and megaripples measured here developed in different flow regimes. To illustrate this, the database of flow parameters and bedform heights were separately filtered to remove data for which (1) wave ripple heights were $<1 \mathrm{~cm}$ and (2) megaripple heights were $<10 \mathrm{~cm}$. The orbital velocity and mean flow conditions under which the larger wave ripples and megaripples existed are identifiable (Fig. 12). There is a clear delineation in between optimum wave ripple conditions $\left(u_{\mathrm{m}}<0.5 \mathrm{~m} / \mathrm{s}\right)$ and optimum megaripple conditions $\left(u_{\mathrm{m}}>\right.$ $0.5 \mathrm{~m} / \mathrm{s}$ ). There is indication that wave ripple development is limited when mean flows are $>0.1 \mathrm{~m} / \mathrm{s}$ and that megaripple development is limited when mean flows are $>0.15 \mathrm{~m} / \mathrm{s}$. The $F_{\text {wr }}$ parameter indicates maximum contribution of wave ripples to the bed elevation variance at low orbital velocities, while at larger orbital velocities, megaripples dominate. Ripple and megaripple heights were independent of wave skewness, as identified by Hay and Mudge (2005).

Wave ripple and megaripple wavelengths were compared to incident wave semi-orbital excursion $A_{\mathrm{s}}$, incident wave orbital velocity and ripple heights (Fig. 13). Wave semiorbital excursion was calculated as $A_{\mathrm{s}}=u_{\mathrm{m}} T / 2 \pi$ (Soulsby
Fig. 6 Suspended sediment parameters calculated at $z=25 \mathrm{~cm}$ above the bed, where $c$ is the suspended sediment concentration in $\mathrm{kg} / \mathrm{m}^{3}$. Sediment transport components are total (i.e. mean + oscillatory) $<u c>$, incident wave $\left\langle u_{g}^{\prime} c_{g}^{\prime}\right\rangle$, low frequency (infragravity) $\left\langle u_{i g}^{\prime} c_{i g}^{\prime}\right\rangle$ and mean $\left.\langle u\rangle<c\right\rangle$. Negative values indicate offshore sediment transport. Units of the transport components are in $\mathrm{kg} / \mathrm{m}^{2} / \mathrm{s}$
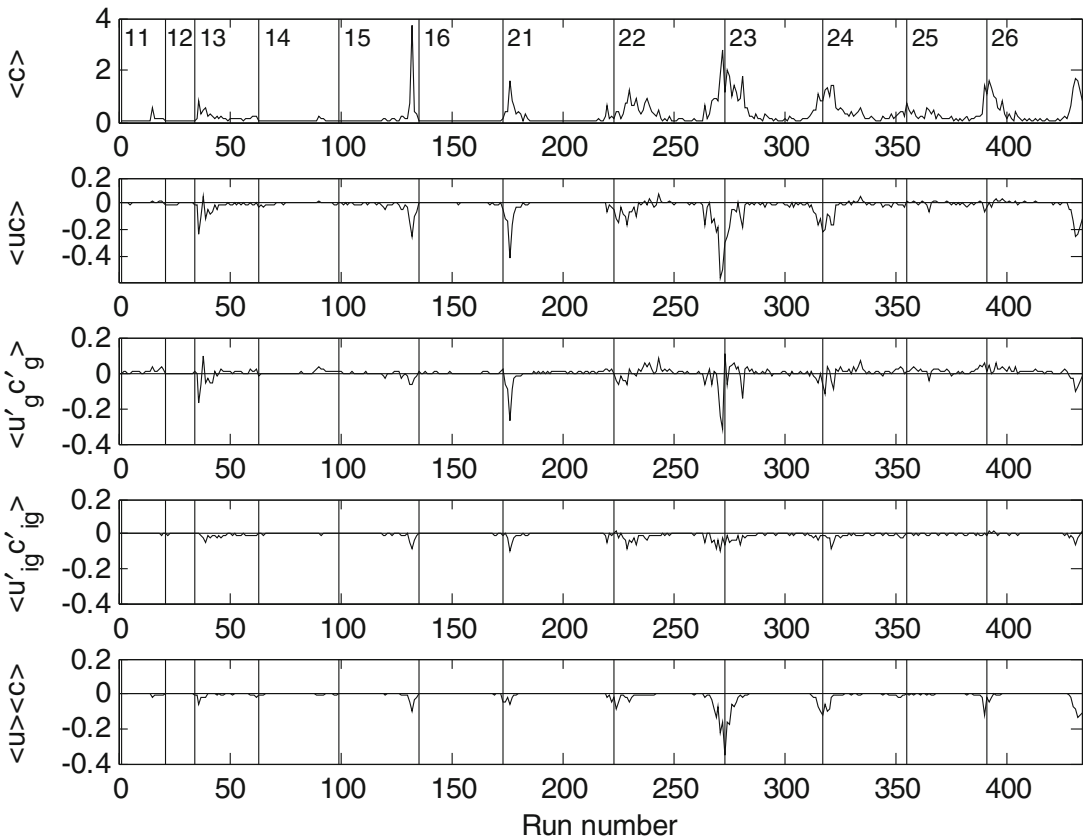
Fig. 7 Timestacks of bedforms measured by the SRP.

Colourscale indicates vertical relief with $+\mathrm{ve}(-\mathrm{ve})$ values in red (blue) and a vertical scale of mm. The SRP is fixed at ' $x=0$ ', and the shore is towards the base of the plot. Data are shown for one scan per minute. Run numbers shown are synchronous with hydrodynamic data, with 1 run= $10 \mathrm{~min}$. Onshore-offshore data resolution is 1 point per $\mathrm{cm}$. Vertical lines indicate the time gaps when the instruments were dry after/before each tide
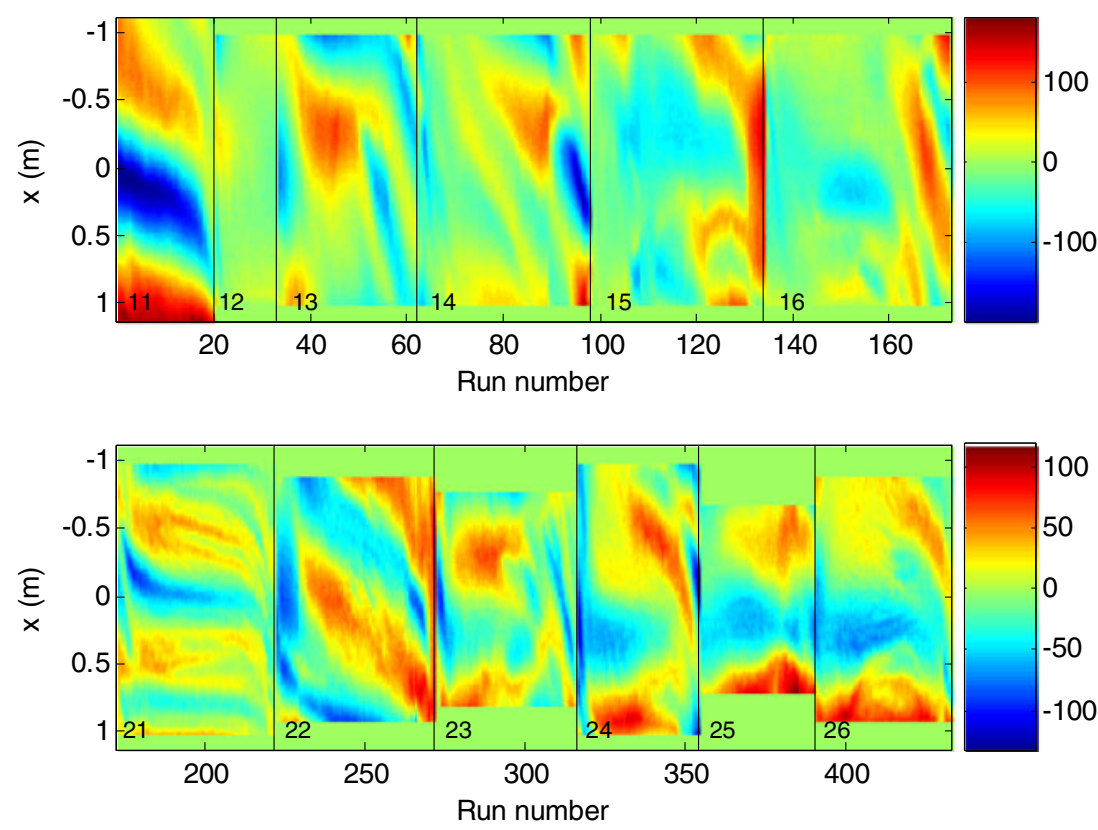

1997). There was considerable scatter in the wave orbital excursion and velocity data, particularly for wave ripples. The larger wave ripples with heights of 1-2 cm existed in orbital excursions 0.3 to $0.77 \mathrm{~m}$ and orbital velocities 0.2 to $0.48 \mathrm{~m} / \mathrm{s}$. When present, their wavelengths were reasonably concentrated in the $15-25 \mathrm{~cm}$ band. Megaripples existed throughout the measured range of semi-orbital excursions $(0.31$ to $1.72 \mathrm{~m})$ and orbital velocities $(0.21$ to $1.11 \mathrm{~m} / \mathrm{s})$. The data suggested $\lambda$ increased with both orbital excursion and orbital velocity, although the large scatter in the data gave a low $r^{2}$. The megaripples with the largest elevation (up to $30 \mathrm{~cm}$ ) had wavelengths up to approximately $1.8 \mathrm{~m}$. Large variations in megaripple wavelengths occurred when the megaripple elevation was small.

\section{Bedform migration}

Bedform migration rates were calculated using a crosscorrelation of time-separated bedform scans (Masselink et al. 2007). This was carried out separately for the filtered wave ripple and megaripple bed data. The lag associated with the largest correlation between the time-separated scans was assumed to represent the distance the bed features had migrated within the time period. Where the correlation coefficient was low $(<0.2)$, the migration rate value was discarded. A scan separation of $5 \mathrm{~min}$ was found to give results that were consistent with close examination of time-separated scans.

Wave ripple and megaripple migrations were found to be predominantly onshore directed, and up to $1.9 \mathrm{~cm} / \mathrm{min}$
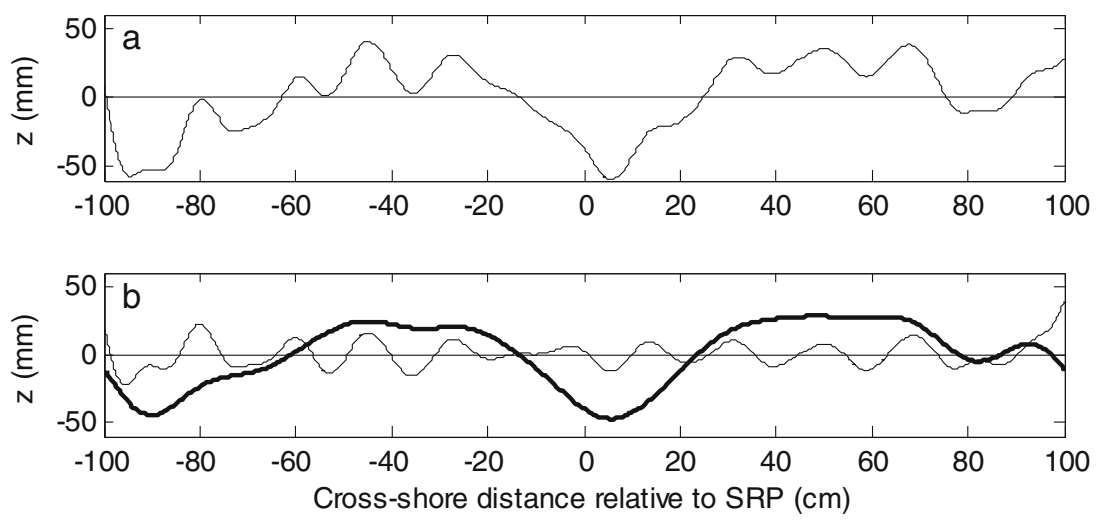

Fig. 8 a Individual line scan under the SRP from tide 21 (run 200). Elevations are shown relative to the mean surface elevation of the scan. The $x$-axis indicates onshore-offshore distance from the centre of the scan. + ve is shoreward. Ripples of length $20 \mathrm{~cm}$ are superimposed on a megaripple of length $\sim 1 \mathrm{~m}$. b Application of a low-pass and high-pass filter (cut-off at $\lambda=35 \mathrm{~cm}$ ) allows the wave ripple component $(\lambda \sim 20 \mathrm{~cm})$ to be separated out from the underlying megaripple $(\lambda \sim 1 \mathrm{~m})$ 
Fig. 9 Bedform parameters: heights of wave ripples $\eta_{\mathrm{wr}}$, megaripples $\eta_{\mathrm{mr}}$ and the fractional contribution of the wave ripples to total bed roughness $F_{\text {wr }}$
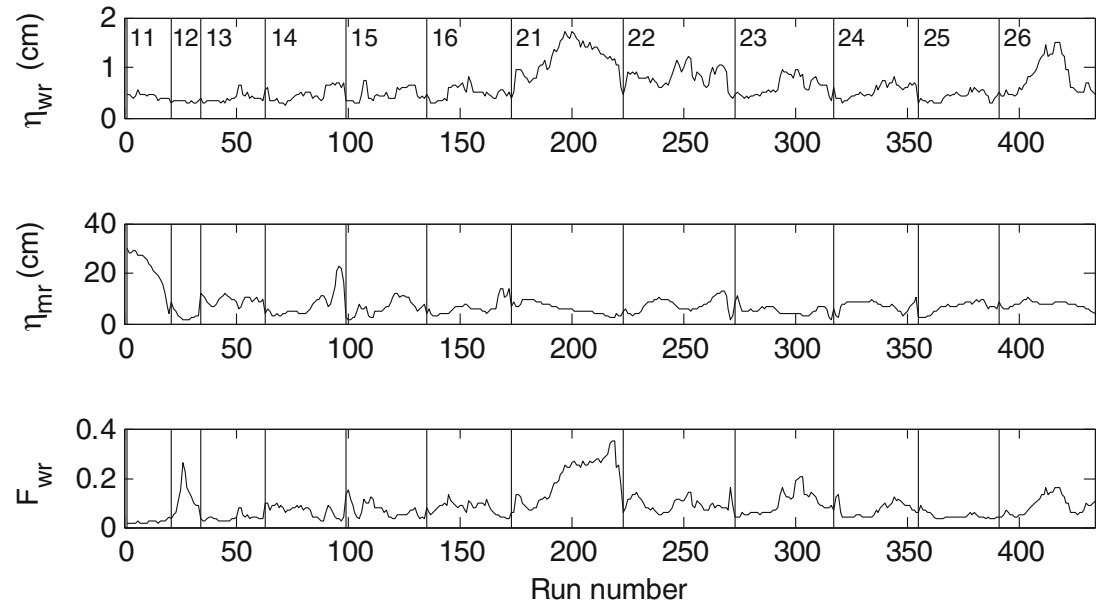

(Fig. 14). Wave ripples (tide 21) and megaripples generally migrated most quickly at the beginning or end of the tide, when the wave orbital velocities and wave skewness were largest. At the end of tide 21, the megaripples (and wave ripples) migrated offshore briefly, and this may be due to the increasing influence of the mean offshore flow and smaller wave heights in this tide.

Wave ripple and megaripple shoreward migration generally increased with wave skewness, despite scatter in the data (Fig. 15). When the larger wave ripples $(>1 \mathrm{~cm})$ were migrating, a reasonably linear relationship between skewness and migration was evident. Although a similar relationship appears in the megaripple data, the scatter was large. Wave ripples migrated most quickly when orbital velocities were in the range 0.3 to $0.65 \mathrm{~m} / \mathrm{s}$. Megaripple migration rates generally increased with increasing orbital velocities. Onshore-directed wave ripple and megaripple migration rates reduced as the offshore-directed mean flow speed increased. For wave ripples, the shoreward migration stopped when mean flows were $<-0.1 \mathrm{~m} / \mathrm{s}$. Shoreward migration of megaripples was halted when offshore-directed mean flows were $<-0.15 \mathrm{~m} / \mathrm{s}$. These data suggest that the resultant migration direction (onshore/halted/offshore) depends on the competition between skewness, orbital velocity and mean flow.

The link between mean flow, skewness and migration rate suggests that migration rates might follow a pattern in relation to the surf zone position linked to wave shoaling, dissipation and undertow. Ruessink et al. (1998) and Masselink et al. (2007) identified that the ratio of wave height to water depth $H / h$ could be used as an indicator of surf zone position. $H / h$
Fig. 10 Bedform parameters: wavelength $\lambda$ and steepness $\eta / \lambda$ of wave ripples ${ }_{w r}$ and megaripples $\mathrm{mr}$
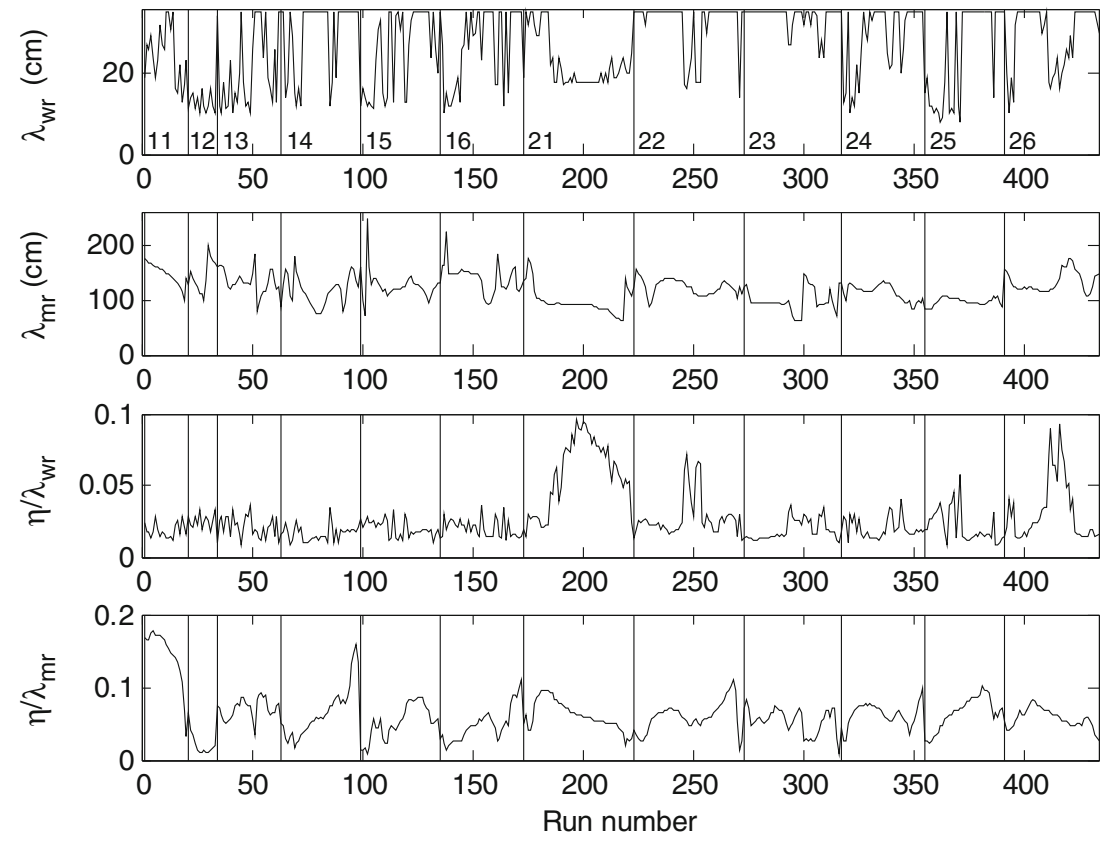
values are low in deep water and increase as waves shoal towards the breakpoint. In these data, the likely position of the edge of the surf zone in terms of $H / h$ is identifiable in the orbital velocity data and the skewness data (Fig. 16). Orbital velocity increases with increasing $H / h$ and reaches a maximum at roughly $H / h=0.5$. It was difficult to specify a consistent value of $H / h$ at the breakpoint for all the data, due to uncertainties arising from scatter, so $H / h$ is therefore used here as a broad guide in describing the cross-shore distribution of velocity based parameters and bedform migration rates. Migration rates of megaripples only are presented in this section, because they were present at the site for a larger number of tides.

Orbital velocity and both gravity band and infragravity band cross-shore velocity variance generally increased through the shoaling zone towards the surf zone. Skewness also increased towards the surf zone as the waves shoaled. Mean flows were offshore directed in most of the data and increased with $H / h$, suggesting increasing importance of undertow closer to the shore. Despite considerable scatter in the data, megaripple heights appear to increase from the shoaling zone to just outside the breakpoint and reduce inside the surf zone. Megaripple migration was generally onshore directed. Migration rates increased towards the breakpoint were maximum at approximately the breakpoint and reduced in the surf zone. The distribution of migration appears to be in response to the balanced contributions of orbital velocity facilitating migration, skewness driving onshore migration and mean offshore-directed flow opposing this onshore migration.

The sediment flux measurements suggest that the total suspended sediment transport at $z=25 \mathrm{~cm}$ is generally offshore and is therefore in the opposite direction to the bedform migration (Fig. 17). Despite the apparent link between wave shape forcing through velocity skewness and bedform migration, there appears to be no link between megaripple migration and the measured suspended sediment transport rates. Migration rates measured were often zero when suspended transport was relatively large, and rapid migration sometimes took place when suspended sediment transport was close to zero. Peculiarly, there was no particular relationship observed for incident waves (e.g. where wave skewness might drive onshore transport and migration) or mean flow (e.g. where a strong offshore flow might give offshore transport and therefore reduce the onshore migration rate). It is likely that the processes driving bedform migration are taking place below the height of the sensor, possibly as bedload. In these data at least, and as far as the instrument sensitivity allows in these data, the bedform migration appears to be decoupled from the suspended sediment transport measured at $25 \mathrm{~cm}$ above the bed and from that predicted using data from $5 \mathrm{~cm}$ above the bed.

\section{Discussion}

Instruments on the rig in this experiment were deployed near the low water mark, and at times, it was possible to see the bedforms at low tide. This gives confidence in the presentation of megaripple data from the SRP and in the approximate magnitudes of the values presented. Ripple alignment and the three-dimensional nature of ripple fields are potential problems in using measurements from ripple profiling sonars. If bedforms crests are not perpendicular to the line of the scan, the wavelength is likely to be overestimated, and in three-
Fig. 11 Height of wave ripples $\eta_{\mathrm{wr}}$ and megaripples $\eta_{\mathrm{mr}}$ against mean velocity $\langle u\rangle$, orbital velocity $u_{\mathrm{m}}$ and mobility number $\psi$
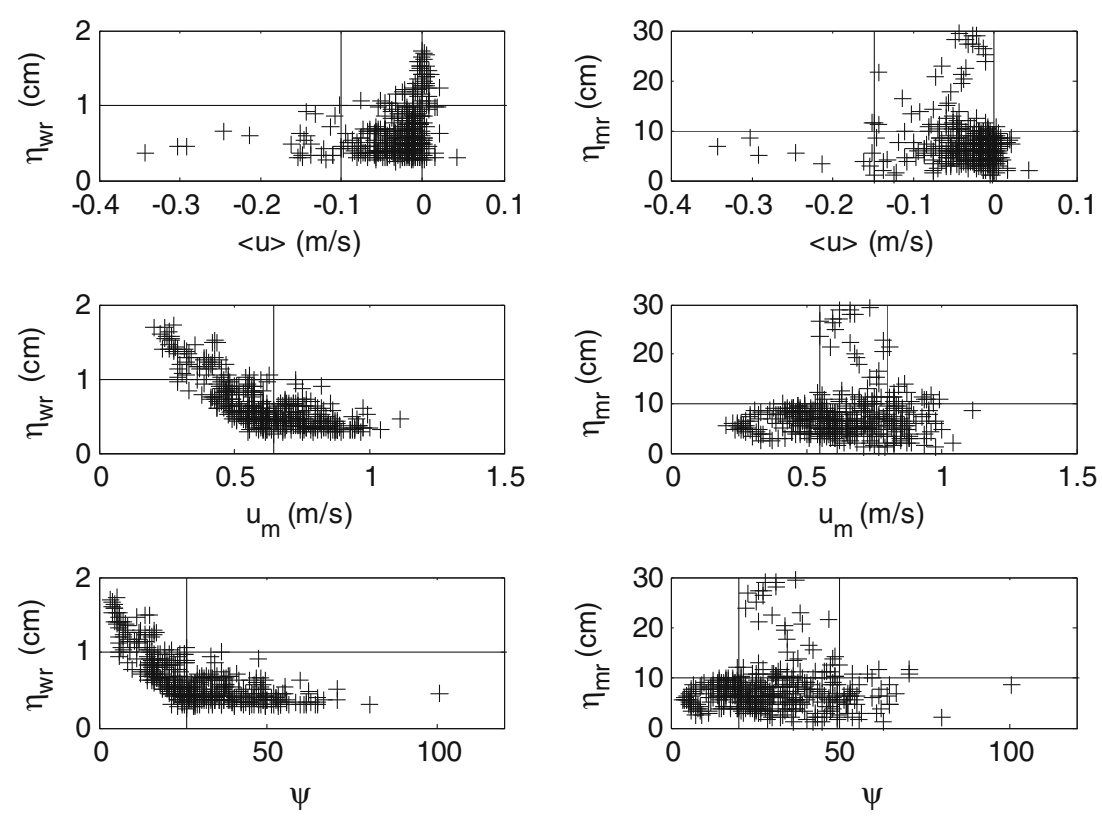
Fig. 12 a Flow conditions when wave ripple heights were $>1 \mathrm{~cm}$ (dots) and when megaripple heights were $>10 \mathrm{~cm}$ (crosses). b Wave ripple contribution to total bed variance $F_{\text {wr }}$ at different orbital velocities (all data)
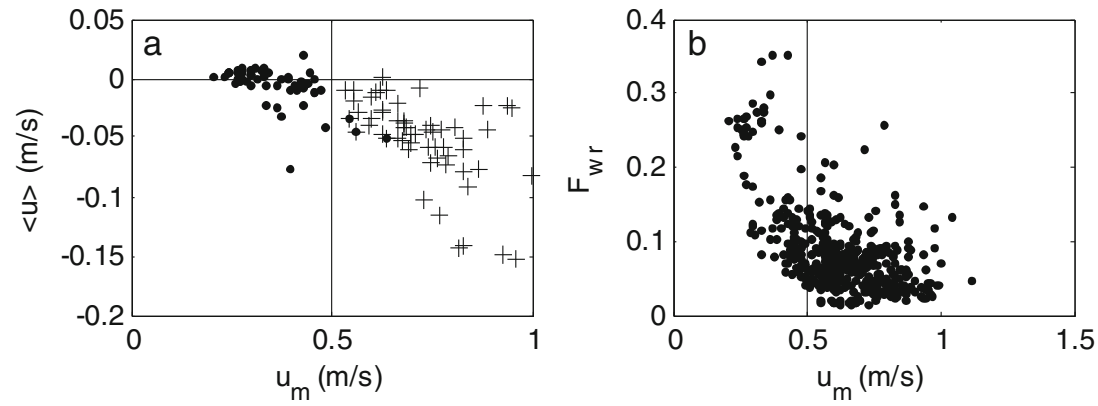

dimensional ripple fields, if the ends of crests or troughs pass through the instrument array, bedform heights may be underestimated. Supporting the data here, visual observations by wading and swimming indicated the following: the megaripples persisted as the water depth increased; they were aligned with crests running alongshore; they were approximately perpendicular to the line of the scan and were reasonably alongshore uniform; and they covered an extensive alongshore and cross-shore area in the region of the instruments.

Some features apparent to the eye in Fig. 7 appear to be not well identified by the migration calculation leading to Fig. 14 (e.g. an apparent shoreward migration around run 250). This may be because the correlation was insufficiently large between scans, leading to a return of zero for $M r$ (e.g. if the shape of the ripple evolves). Differences may also result because the eye is able to give an overall impression of change, by averaging over many different time lags. The results indicate migration rates that are of broadly similar magnitude to previous measurements by Masselink et al. (2007) and are consistent with close examination of the time-separated scans. For the megaripples, filtering out the wave ripples gave a much clearer migration rate than carrying out the cross-correlation approach on an unfiltered bedform trace.

The wave ripples in this data are in the length range indicated by Yalin (1964) for current ripples, with $\lambda=1,000 \mathrm{D}$ giving a length of $28 \mathrm{~cm}$ and a height of $\eta=\lambda / 7=4 \mathrm{~cm}$. However, their height reduced as the current and associated shear stress increased (Fig. 11), suggesting that they are unlikely to be current ripples. The height of the wave ripples $(1-2 \mathrm{~cm})$ and their length of $20 \mathrm{~cm}$ gives them a characteristic steepness of 0.05 to 0.1 . They are therefore likely to be 'post-vortex' wave ripples, in Bagnold's (1963) classification.

The megaripples have length scales similar to those expected for current dunes in the shallowest water levels measured. However, their height reduced with increasing current (Fig. 11), and so they are unlikely to be current dunes. They have length scales and heights that tie in with Gallagher et al.'s
Fig. 13 Wavelength $\lambda$ of wave ripples $_{\mathrm{wr}}$ and megaripples ${ }_{\mathrm{mr}}$ against semi-orbital excursion $\mathrm{A}_{\mathrm{s}}$, orbital velocity $u_{\mathrm{m}}$ and ripple height $\eta$. Wave ripple data are separated into ripple heights $>1 \mathrm{~cm} \mathrm{(+)} \mathrm{and}<1 \mathrm{~cm}(\mathrm{x})$
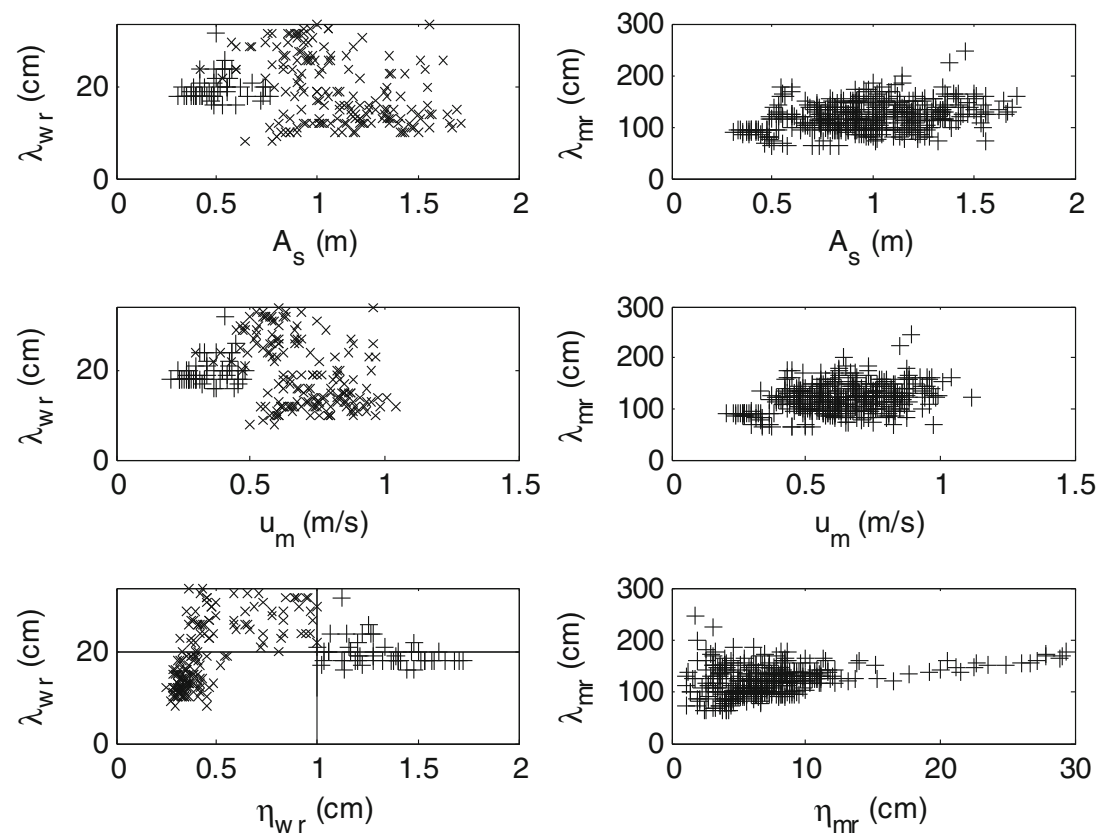
Fig. 14 Bedform migration rates for wave ripples $M r_{\mathrm{wr}}$ and megaripples $M r_{\mathrm{mr}}$ +ve migration indicates ripples moving shoreward. Dots at the top of the upper panel indicate runs when the wave ripple height was $>1 \mathrm{~cm}$
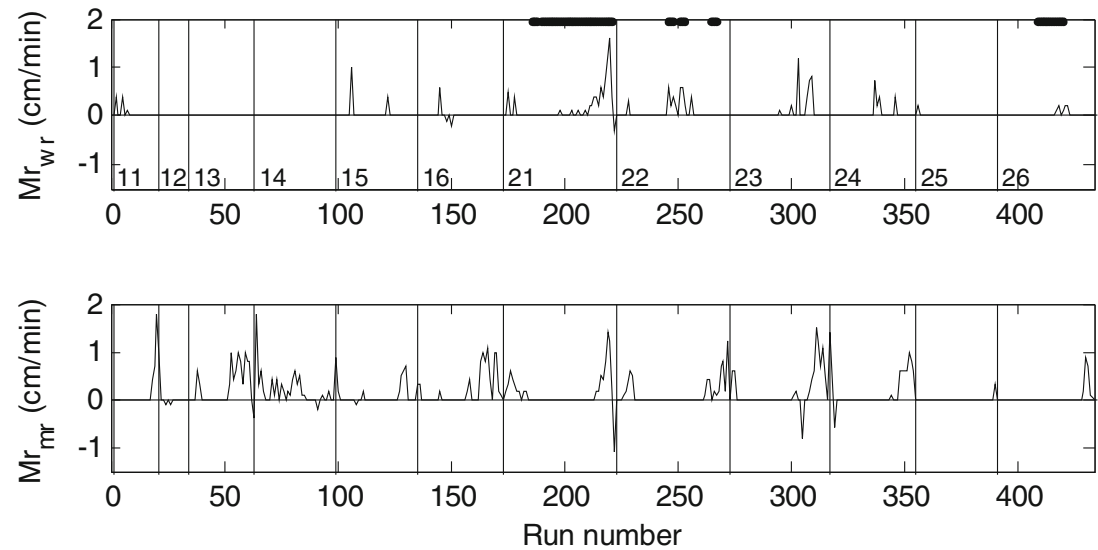

(1998) classification for 'megaripples', and exist in similar mobility number conditions to those observed by Gallagher et al. (2003).

Wave ripples and megaripples were able to occur simultaneously in this experiment in relatively low wave energy conditions $\left(u_{\mathrm{m}}<\sim 0.65 \mathrm{~m} / \mathrm{s}\right)$ (Fig. 11), when mean currents were small $(<\mathrm{u}><\sim 0.1 \mathrm{~m} / \mathrm{s}$ ), (cf. Blondeaux et al. 2000). This occurred for mobility numbers $\psi<25$. In increasingly high energy conditions, it appears that the wave ripples disappear first and that megaripples remain.

The data presented here suggests that the conditions in which the highest wave ripples develop is separated from the conditions for which the highest megaripples develop by an orbital velocity threshold of $\sim 0.5 \mathrm{~m} / \mathrm{s}$ (Fig. 12). Hay and Mudge (2005) found a similar delineation, in which the lowest RMS velocities in which megaripples occurred was $\sim 0.28 \mathrm{~m} / \mathrm{s}$, and below this linear transition ripples occurred. They also found overlap between the two regimes. Their RMS velocity is equivalent to a $u_{\mathrm{m}}$ value of $0.56 \mathrm{~m} / \mathrm{s}$ in this analysis. Some scatter in the data across this delineation may exist because the bedforms take time to respond when the hydrodynamic conditions change. Austin et al. (2007) identify that wave ripples respond in time frames of 5-10 min provided the hydrodynamic conditions remain sufficient energetic. In this analysis, the parameters are calculated for 10-min sections of data, and although the depth and orbital velocity changes are assumed to be slow relative to the $5-10 \mathrm{~min}$ relaxation time identified by Austin et al. (2007), there may be some lag in bedform response that means they are slightly out of phase.

Although a band of mobility numbers were identifiable in which large megaripple features developed, conditions were not measured in sufficiently high mobility numbers for the bed
Fig. 15 Migration rate of wave ripples $M r_{\mathrm{wr}}$ and megaripples $M r_{\text {mr }}$ against mean velocity $\langle u>$, incident wave velocity skewness $S_{u}$ and orbital velocity $u_{\mathrm{m}}$. Wave ripple data are separated into ripple heights $>1 \mathrm{~cm}(+)$ and $<1 \mathrm{~cm}(x)$
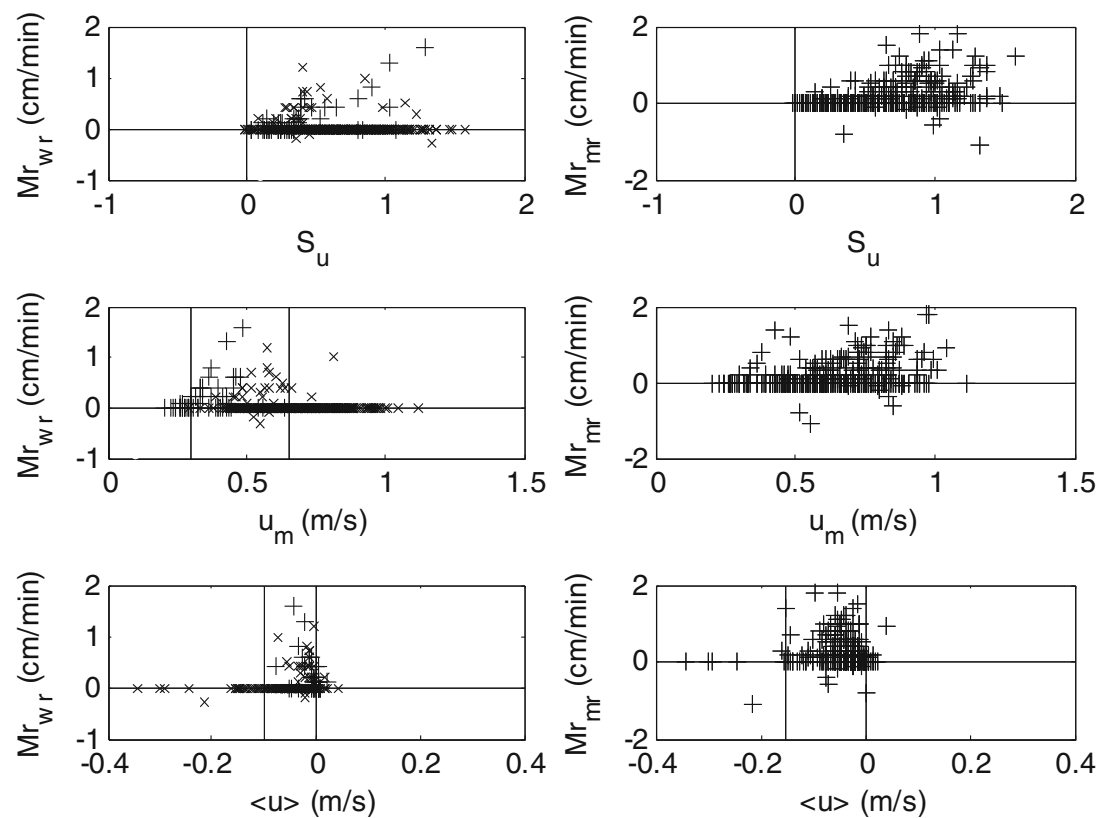
Fig. 16 Orbital velocity, gravity band $(+)$ and infragravity band $(\cdot)$ cross-shore velocity variance, wave skewness, mean cross-shore flow velocity, megaripple height and megaripple migration rate as a function of wave height/water depth. The $H / h=0.5$ delineation indicates the approximate boundary between shoaling and surf zones
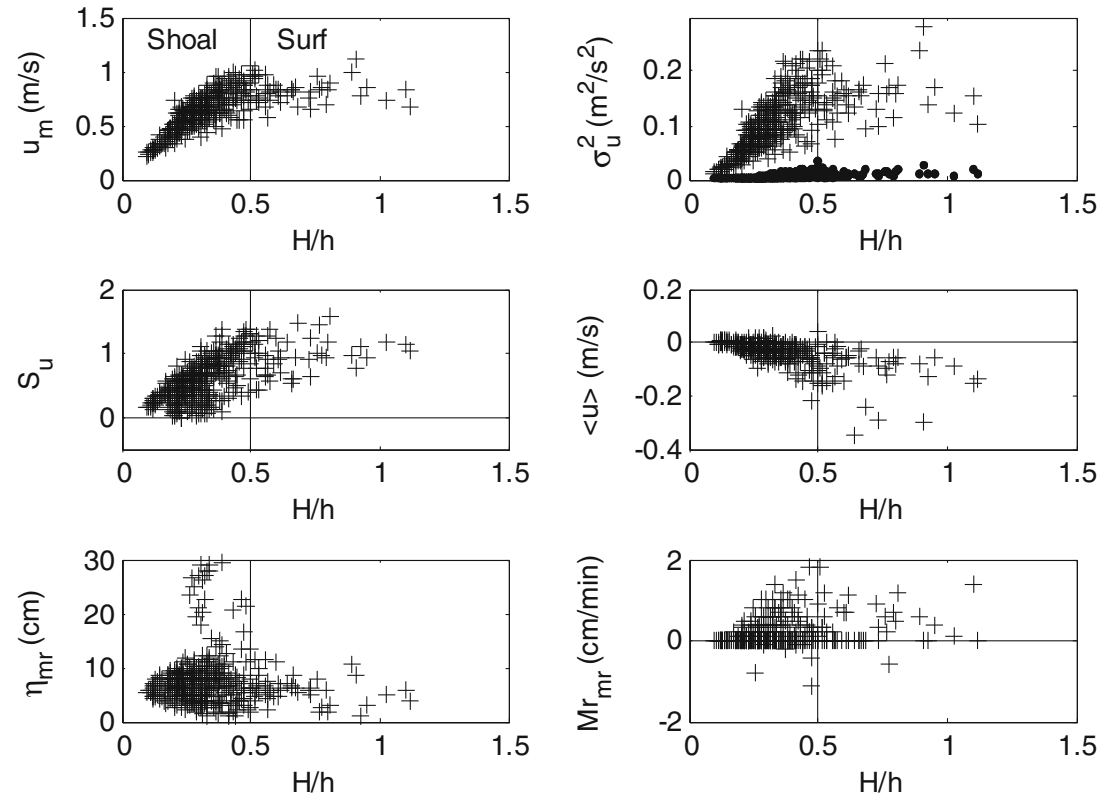

to flatten. Data were mainly gathered with $\psi<70$ (Fig. 11), while Gallagher et al. (2003) indicate bed flattening occurs at $\psi \sim 100$. In terms of cross-shore distribution, the largest megaripples occurred just outside the breakpoint, similar to SCUBA observations by Clifton et al. (1971), and reduced in size in the surf zone. However, the bed did not appear to flatten at the breakpoint in this data, possibly because the dissipative nature of wave breaking at this site did not give rise to sufficient turbulence at the bed, or the mobility number was not sufficiently large.
Both megaripples and wave ripples migrated shoreward (Fig. 15) and generally moved in the direction of wave skewness, as observed by Crawford and Hay (2001). Masselink et al. (2007) also documented an onshore migration direction, and a reduction in migration rates in the deeper water in the shoaling zone, compared to the outer surf zone. This supports the observation (Fig. 15) that increases in wave skewness associated with wave shoaling give rise to increased onshore migration rates. Like Masselink et al.'s (2007) data from the inner surf zone, the migration rates reduced in shallow water
Fig. 17 Megaripple migration rates versus suspended sediment transport parameters calculated at $z=25 \mathrm{~cm}$ above the bed including total (i.e. mean + oscillatory) $<u c>$, high frequency (incident wave component) $\left\langle u_{g}^{\prime} c_{g}^{\prime}\right\rangle$, low frequency (infragravity) component $\left\langle u_{i g}^{\prime} c_{i g}^{\prime}\right\rangle$ and the mean component $\langle u\rangle\langle c\rangle$ of transport
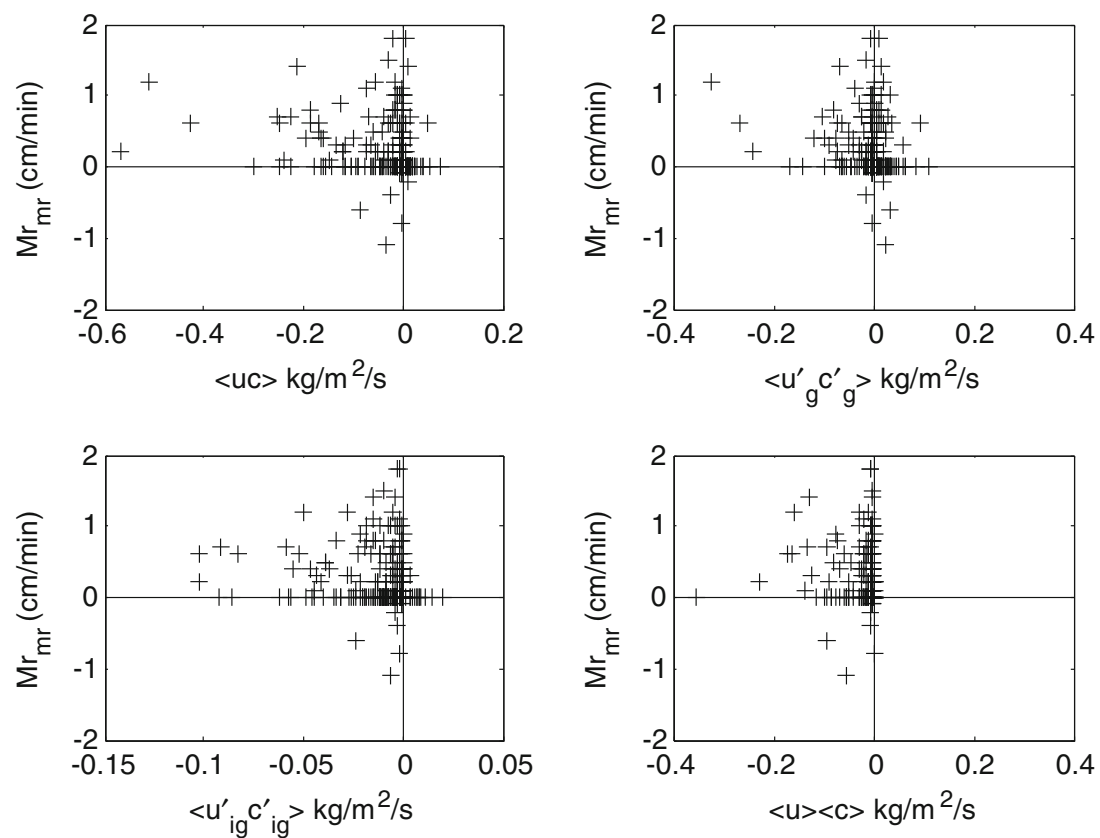
in this data (Fig. 16), and in this case, this happened when the offshore-directed flow increased. Ngasuru and Hay (2004) also found a reduction in onshore migration when an offshore-directed mean flow was present.

No clear pattern was evident in the wave asymmetry values in this data in relation to ripple migration. Positive (onshore directed) wave asymmetry was identified in the velocity signal for water depths $<1 \mathrm{~m}$ in the data when the SRP measurements were not possible, and it is therefore possible that wave asymmetry contributes to bedform forcing in shallow water, but the relationship was not measurable in this experiment.

Generally, offshore-directed flows in the surf zone may be due to undertow (e.g. Masselink and Black 1995) or may be part of a rip current circulation (Thorpe et al. 2013). Sherman et al.'s (1993) data indicated that in conditions where the flow strength is strong in a feeder channel of a rip current, the balance may be in favour of the mean flow, and the resulting megaripple migration followed the mean flow direction (offshore) rather than the wave direction (onshore). In the second six tides of data here, the trough may also have experienced occasional rip current conditions when the water was shallow $(\sim 1 \mathrm{~m})$. This would increase the offshore-directed mean flow component in the velocity data and possibly contributes to the offshore-directed migration at the very end of tide 21 (Fig. 14). The specific conditions of sediment transport and bedform migration in rip currents with large offshore-directed mean flows are subject to further study (e.g. Thorpe et al. 2013).

The data here suggest that the suspended sediment transport is directed offshore for the majority of the time (Fig. 17). Offshore sediment transport at incident wave frequencies in the region just seaward of the breakpoint, in conditions likely to have supported a rippled bed, have also been observed by Davidson et al. (1993). A mechanism for this process was identified by Inman and Bagnold (1963), who suggested that the release of a sediment vortex at the start of the offshoredirected stroke of the wave could result in a net offshore suspended transport above a ripple field. Similar observations (i.e. offshore-directed suspended sediment transport above shoreward-migrating ripples) were made by Traykovski et al. (1999), who hypothesized that the onshore migration may be due to an unmeasured bedload transport.

Morphologically, the measurements at Perranporth represent a dissipative macrotidal beach. This is in contrast to the microtidal barred beach at Duck, which has a small tidal range, and a distinct bar-trough morphology. Both have fine sand, and in similar mobility numbers, megaripples develop in the surf zone at both sites (Thornton et al. 1998; Gallagher et al. 2003; Ngasuru and Hay 2004). A key difference is that at Perranporth, the bed has to react to incident wave conditions that vary as a result of water depth change on a tidal time scale, as well as with offshore wave conditions, and this possibly contributes to the variability in the data here. Further contrast is given by comparison with observations at an intermediate macrotidal coarse grained beach with a low tide terrace morphology at Sennen, UK (Austin et al. 2007; Masselink et al. 2007). Masselink et al. (2007) used the change in bedform dynamics at a point location with changing tide height, to identify a similar cross-shore migration pattern relative to surf zone position as found in this data. However, despite similar mobility number conditions, the bedform wavelengths at Sennen were indicative of wave ripples (wavelengths 28 to $38 \mathrm{~cm}$, and heights 4.5 to $5.5 \mathrm{~cm}$ ), while at Perranporth and Duck, the bedform features are megaripple scale. The most obvious difference to explain this is that Sennen has a more coarse grain size $\left(D_{50}=0.69\right)$ compared to Perranporth $\left(D_{50}=\right.$ $0.28 \mathrm{~mm})$ and Duck $(D=0.2 \mathrm{~mm})$. The average beach slope is also steeper at Sennen: $\tan \beta=0.08$ on the upper beach and 0.03 on the terrace, compared to 0.0125 at Perranporth and 0.014 over a cross-shore distance of $350 \mathrm{~m}$ at Duck. In synthesis, it appears that finer grained, dissipative beaches may be more likely to lead to megaripples and that these features are likely to migrate according to their cross-shore position relative to the surf zone, as driven by the balance of wave skewness, orbital velocity and mean flow.

\section{Conclusion}

Wave ripples with heights up to $2 \mathrm{~cm}$ and lengths of $\sim 20 \mathrm{~cm}$ were observed to develop on a sandy dissipative beach in low energy conditions $\left(u_{\mathrm{m}}<0.65 \mathrm{~m} / \mathrm{s}\right)$, corresponding to mobility numbers $<25$. Wave ripple heights decreased with increasing orbital velocity and with increased mean current strength. Wave ripples were superimposed on top of small megaripples in these low energy conditions and contributed at most $35 \%$ of the total bed roughness. In higher energy conditions, the wave ripples flattened, and the seafloor was dominated by megaripples. Megaripples had heights $10-30 \mathrm{~cm}$ and lengths of 1-1.8 m. Megaripples were largest when orbital velocities were in the range 0.5 to $0.8 \mathrm{~m} / \mathrm{s}$ and when mean currents were weak $(\sim 0.05 \mathrm{~m} / \mathrm{s})$, corresponding to mobility numbers in the range $25-50$.

Wave ripple and megaripple migrations were generally onshore, and migration rates reached $1.9 \mathrm{~cm} / \mathrm{min}$. Migration rates increased with orbital velocity and +ve (shoreward directed) wave skewness but were reduced by an offshoredirected mean flow. Shoreward migration was halted for offshore flows $>0.15 \mathrm{~m} / \mathrm{s}$. Measured suspended sediment transport was generally directed offshore; however, no clear link was evident between bedform migration and suspended sediment transport rates. The pattern of migration appeared to be linked to surf zone position. Migration increased shorewards towards the breakpoint with wave shoaling and reduced inside the surf zone due to the effect of undertow. 
Acknowledgments The fieldwork for this project was funded by a partnership grant from the UK Natural Environment Research Council (NERC) and the UK Royal National Lifeboat Institution (RNLI), 'Dynamics of Rip Currents and Implications for Beach Safety (DRIBS)', (NERC ref: NE/H004262/1).

\section{References}

Allen JRL (1968) Current ripples. North-Holland, Amsterdam

Austin MJ, Masselink G, O'Hare TJ, Russell PE (2007) Relaxation time effects of wave ripples on tidal beaches. Geophys Res Lett 34, L16606. doi:10.1029/2007GL030696

Austin MJ, Scott TM, Brown JW, Brown JA, MacMahan JH, Masselink G, Russell PE (2010) Temporal observations of rip current circulation on a macro-tidal beach. Cont Shelf Res 30:1149-1165. doi:10. 1016/j.csr.2010.03.05

Bagnold RA (1963) Beach and nearshore processes. In: Hill MN (ed) The Sea. Wiley, New York, pp 507-553

Bailard JA (1981) An energetics total load sediment transport model for a plane sloping beach. J Geophys Res 86:10938-10954

Blondeaux P, Foti E, Vittori G (2000) Migrating sea ripples. Eur J Mech B Fluid 19(2):285-301

Butt T, Miles JR, Ganderton P, Russell PE (2002) A simple method for calibrating opptical backscatter sensors in high concentrations of non-cohesive sediments. Mar Geol 192:419-424

Clarke LB, Werner BT (2004) Tidally modulated occurrence of megaripples in a saturated surf zone. J Geophys Res 109, C01012. doi:10.1029/2003JC001934

Clifton HE, Hunter RE, Phillips RL (1971) Depositional structures and processes ni the non-barred high energy nearshore. J Sediment Petrol 41(3):651-670

Crawford AM, Hay AE (2001) Linear transition ripple migration and wave orbital velocity skewness: observations. J Geophys Res 106(14):113-14, 128

Crawford AM, Hay AE (2003) Wave orbital velocity skewness and linear transition ripple migration: comparison with weakly nonlinear theory. J Geophys Res 108(C3), 3091. doi:10.1029/2001JC001254

Davidson MA, Russell PE, Huntley DA, Hardisty J (1993) Tidal asymmetry in suspended sand transport on a macrotidal intermediate beach. Mar Geol 110:333-353

Davidson M, Huntley D, Holman R, George K (1997) The evaluation of large scale $(\mathrm{km})$ intertidal beach morphology on a macrotidal beach using video images. Proceedings Coastal Dynamics 97:385-394

Doucette JS (2002) Bedform migration and sediment dynamics in the nearshore of a low energy sandy beach in southwestern Australia. J Coast Res 18:576-591

Dyer KR (1986) Coastal and estuarine sediment dynamics. Wiley, Chichester

Elgar S, Guza RT, Freilich M (1998) Eulerian measurements of horizontal accelerations in shoaling surface gravity waves. J Geophys Res 93 : 9261-9269

Gallagher EL (2003) A note on megaripples in the surfzone: evidence for their relation to steady flow dunes. Mar Geol 193:171-176
Gallagher EL (2011) Computer simulations of self-organised megaripples in the nearshore. J Geophys Res 116F01004. doi:1029/2009JF001473

Gallagher EL, Elgar S, Thornton EB (1998) Megaripple migration in a natural surfzone. Nature 394:165-168

Gallagher EL, Thornton EB, Stanton TP (2003) Sand bed roughness in the nearshore. J Geophys Res 108 C2 3039 doi:10.1029/ 2001JC001081

Gallagher EL, Elgar S, Guza RT, Thornton EB (2005) Estimating nearshore bedform amplitudes with altimeters. Mar Geol 216:51-57. doi:10.1016/j.margeo.2005.01.005

Hay AE, Mudge T (2005) Principal bed states during SandyDuck97: occurrence, spectral anisotropy, and the bed state storm cycle. J Geophys Res 110, C03013. doi:10.1029/2004JC002451

Jaffe BE, Sternberg RW, Sallenger AH (1984) The role of suspended sediment in shore normal beach profile changes. Proceedings 19th International Conference on Coastal Engineering. ASCE, Houston

Masselink G, Black KP (1995) Magnitude and cross-shore distribution of bed return flow on natural beaches. Coast Eng 25:165-190

Masselink G, Hughes MG (2003) Introduction to coastal processes \& geomorphology. Hodder Education, London

Masselink G, Austin M, O’Hare T, Russell P (2007) Geometry and dynamics of wave ripples in the nearshore of a coarse sandy beach. J Geophys Res 112, C10022. doi:10.1029/2006JC003839

Ngasuru AS, Hay AE (2004) Cross-shore migration of lunate megaripples during Duck94. J Geophys Res 109:C02006. doi:10. 1029/2002JC001532

Nielsen P (1992) Coastal bottom boundary layers and sediment transport. Advanced series on ocean engineering. World Scientific, London

Ruessink BG, Houwman KT, Hoekstra P (1998) The systematic contribution of transporting mechanisms to the cross-sore sediment transport in water depths 3-9m. Mar Geol 152:295-324

Sherman DJ, Short AD, Takeda I (1993) Sediment mixing-depth and bedform migration in rip channels. J Coast Res 15:39-48

Soulsby RL (1997) Dynamics of Marine Sands, Thomas Telford Publications

Thornton EB, Swayne JL, Dingler (1998) Small scale morphology across the surf zone. Mar Geol 145:173-196

Thorpe A, Miles J, Masselink G, Russell P, Scott T, Austin M (2013) Sediment transport in rip currents on a macrotidal beach. Proceedings 12th International Coastal Symposium (Plymouth, England), J Coast Res. SI 65 pp 1880-1885, ISSN 0749-0208. doi: 10.2112/S165-318.1.

Traykovski P, Hay AE, Irish JD, Lynch JF (1999) Geometry, migration, and evolution of wave orbital ripples at LEO-15. J Geophys Res 104:1505-1524

Vincent CE, Osborne PD (1993) Bedform dimensions and migration rates under shoaling and breaking waves. Cont Shelf Res $13: 1267-1280$

Wright LD, Boon JD, Kim SC, List JH (1991) Modes of cross-shore sediment transport on the shoreface of the Middle Atlantic Bight. Mar Geol 96:19-51

Yalin MS (1964) On the average velocity of flow over a mobile bed. La Houille Blanche 1:45-53 